\title{
Comparison of Land Surface Temperature During and Before The Emergence of Covid-19 Using Modis Imagery in Wuhan City, China
}

\author{
Hamim Zaky Hadibasyir ${ }^{1, *}$, Seftiawan Samsu Rijal ${ }^{2}$, Dewi Ratna Sari ${ }^{3}$ \\ ${ }^{1}$ Faculty of Geography, Universitas Muhammadiyah Surakarta, 57162 Surakarta City, Indonesia \\ ${ }^{2}$ Marine Science Department, Faculty of Fisheries and Marine Science, Universitas Brawijaya, 65145 \\ Malang City, Indonesia \\ ${ }^{3}$ World Resources Institute (WRI) Indonesia, 12170 South Jakarta City, Indonesia \\ *) Corresponding Author (e-mail: hamim.zaky.h@ums.ac.id)
}

Received: 08 May 2020 / Accepted: 27 May 2020 / Published: 11 June 2020

\begin{abstract}
Coronavirus disease (COVID-19) was firstly identified in Wuhan, China. By 23rd January 2020, China's Government made a decision to execute lockdown policy in Wuhan due to the rapid transmission of COVID-19. It is essential to investigate the land surface temperature (LST) dynamics due to changes in level of anthropogenic activities. Therefore, this study aims (1) to investigate mean LST differences between during, i.e., December 2019 to early March 2020, and before the emergence of COVID-19 in Wuhan; (2) to conduct spatiotemporal analysis of mean LST with regards to lockdown policy; and (3) to examine mean LST differences for each land cover type. MODIS data consist of MOD11A2 and MCD12Q1 were employed. The results showed that during the emergence of COVID-19 with lockdown policy applied, the mean LST was lower than the mean LST of the past three years on the same dates. Whereas, during the emergence of COVID-19 without lockdown policy applied, the mean LST was relatively higher than the mean LST of the past three years. In addition, the mean LST of built-up areas experienced the most significant differences between during the emergence of COVID-19 with lockdown policy applied in comparison to the average of the past three years.
\end{abstract}

Keywords: urban climate; Severe Acute Respiratory Syndrome Coronavirus 2 (SARS-CoV-2); Wuhan's lockdown; anthropogenic activities; remote sensing

\section{Introduction}

Severe Acute Respiratory Syndrome Coronavirus 2 (SARS-CoV-2), a new type virus from coronavirus mutation which causes Coronavirus Disease 2019 (COVID-19), was firstly identified in Wuhan City, Hubei Province, China in December 2019 (Kong et al., 2020). In China itself, by the middle week of January 2020, about one person died, and more than 40 persons clinically confirmed affected by the new virus (Qin \& Hernández, 2020). By 20th January 2020, there were 278 confirmed cases reported in China. Also, by that time, the disease has been spread to other countries, such as Thailand (2 cases), South Korea (1 case), and Japan (1 case) (World Health Organisation, 2020b). Then, by 11th
March 2020, the World Health Organisation (2020a) classified COVID-19 as a pandemic.

Due to the rapid widespread of the COVID-19, China's Government decided to close Wuhan as the epicentre of the virus as measures for preventing and controlling the spread of the disease (Kuo, 2020). This policy was well-known with 'Lockdown' from January 23rd, 2020, to the next 76 days in Wuhan (McNeil, 2020). During that time, residents of Wuhan City had only been permitted to go outside of their homes to do grocery shopping and fulfilling other crucial needs. Also, most of the public facilities, such as subway, long-distance shuttle bus, city bus, train, and the airport had been closed temporarily (Kuo, 2020). In addition, some big manufacturing companies, such 
as Dongfeng, Xiaomy, Siemens, Dongfeng, BOT Technology Group, had been suspending their operations to prevent the possibility of COVID-19 transmission (Esfandiari, 2020).

Previous studies about COVID-19 with respect to the environment were conducted by Liu et al. (2020) and Tobías et al. (2020). A research conducted by Liu et al. (2020) reveals that meteorological factors have some contribution to shape the COVID-19 transmission to some extent, in which weather with a low level of humidity and mild diurnal temperature range is likely to promote COVID-19 transmission. In addition, a study investigated by Tobías et al. (2020) shows that air quality level had improved as proven by reductions of some pollutant concentrations, such as nitrogen dioxide (NO2), black carbon (BC), and PM10 by two weeks after lockdown policy was implemented. Based on those studies, it can be concluded that COVID-19 brings some consequences to the environment by several means.

Another interesting environmental variable that is important to be investigated due to the emergence of COVID-19 is Land Surface Temperature (LST). LST plays a big role in many studies, such as global climate change, hydrological, agricultural, and urban Land Use Land Cover (LULC) (Avdan \& Jovanovska, 2016). Moreover, LST is becoming a crucial topic of improving the quality of human life as urbanisation continuous throughout the world. Previous studies have been figuring out the link between many factors, such as anthropogenic issues on LST (Buyantuyev \& Wu, 2010; X. Li et al., 2016; Meng \& Dou, 2016). According to Yoo, Im, Park, and Cho (2017) and Wang, Zhan, and Ouyang (2017), urbanisation, transportation, industrial, and residential were the main activities that are potentially linked to LST. It has been found that anthropogenic activities are likely leading to increases in LST. Accordingly, if the rising of anthropogenic activities would increase LST, then there is a possibility that the reduction of anthropogenic activities should also lead to a decrease in LST. In other words, due to limitation of public activities, public transportations as well as some suspended operations of big companies in Wuhan while lockdown policy was implemented, there is a potential impact to LST, in which LST might be lower than normal condition.

The rapid development of remote sensing technology has made earth observation, including LST measurements, can be conducted by means of satellite observations in multi-temporal ways with various spatial and temporal resolutions (Jensen, 2015; Ndossi \& Avdan, 2016). However, in order to monitor LST over several years on a regional scale, an imaging system with the capability of acquiring LST on a daily or weekly basis with broad coverage is necessary. For instance, a study conducted by Eleftheriou et al. (2018) about annual and seasonal LST trends over Greece by using weekly Moderate Resolution Imaging Spectroradiometer (MODIS) LST data at $1 \times 1 \mathrm{~km}$ spatial resolution. Besides, it has been proven by ground-truthing that those LST data showed reliable accuracy from $1 \mathrm{~K}$ to $1.5 \mathrm{~K}$ (Hulley, Hughes, \& Hook, 2012).

With regards to comparing LST variation due to the implementation of lockdown policy in Wuhan, if the investigation just compared LST between during and before lockdown policy was implemented in one period of winter, there would be a possibility that the variations were due to regular seasonal changes overtime per se, instead of owing to lockdown policy's effect. Hence, the investigation should not only compare LST variation between before and during the implementation of lockdown in one season (i.e., December 2019 to February 2020) but also compare to the LST in the previous years, in order to represent a condition before the emergence of COVID-19. LST comparisons during the emergence of COVID-19 (i.e., December 2019 to February 2020) with the LST of several previous years on the same dates (i.e., the past three years) allow exploring a deeper understanding of LST conditions between during and before the emergence of COVID-19. Moreover, during and before the emergence of COVID-19 might bring the different intensity of anthropogenic activities, which could also lead 
to different LST values. In addition, in builtup areas, there is a potential difference in the intensity of anthropogenic activities between during and before the execution of lockdown. It is, therefore, important to incorporate investigation regarding differences of LST for each land cover type in various anthropogenic levels. Based on aforementioned rationales, this study employed MODIS data in order to answer the following research aims, i.e. (1) to investigate mean LST differences between during emergence of COVID-19 and the average of the past three years for the same dates, representing before the emergence of COVID-19, in Wuhan; (2) to conduct spatiotemporal analysis of mean LST between during and before the emergence of COVID-19 with regards to lockdown policy in Wuhan; and (3) to examine mean LST differences between during and before the emergence of COVID-19 for each land cover type with regards to lockdown policy in Wuhan..

\section{Research Method}

\subsection{Study area and data}

Figure 1 illustrates the location of Wuhan City as the study areas with generalised land covers derived from the MODIS land cover dataset as background (MCD12Q1). As a capital city of Hubei Province, Wuhan $\left(29^{\circ} 58^{\prime}\right.$ - $31^{\circ} 22^{\prime} \mathrm{N}, 113^{\circ} 41^{\prime}-115^{\circ} 05^{\prime} \mathrm{E}$ ) lies on the east of Jianghan Plain and the Yangtze River runs through the city. "The Chicago of China" is a home for more than 11 million people. Wuhan City administrative divisions consist of urban districts and suburban districts. Urban districts consist of seven districts, i.e., Qiaokou, Hanyang, Jing'an, Qingshan, Wuchang, Hongshan, and Jianghan. The suburban districts comprise of six districts, i.e., Xinzhou, Dongxihu, Hannan, Huangpi, Caidian, and Jiangxia. The total area of Wuhan is about $8569 \mathrm{~km}^{2}$. The water bodies such as lake and pool extend $2217.6 \mathrm{~km}^{2}$, about more than a quarter of the city. The climate of Wuhan City is subtropical with four prominent seasons throughout a year, i.e., spring, summer, fall, and winter (L. Li et al., 2014). Furthermore, the city experienced the highest temperature in July while the lowest temperature in January, with the average highest and lowest temperatures at around $29.1^{\circ} \mathrm{C}$ and $4.0^{\circ} \mathrm{C}$, respectively (China Meteorological Administration, n.d.).

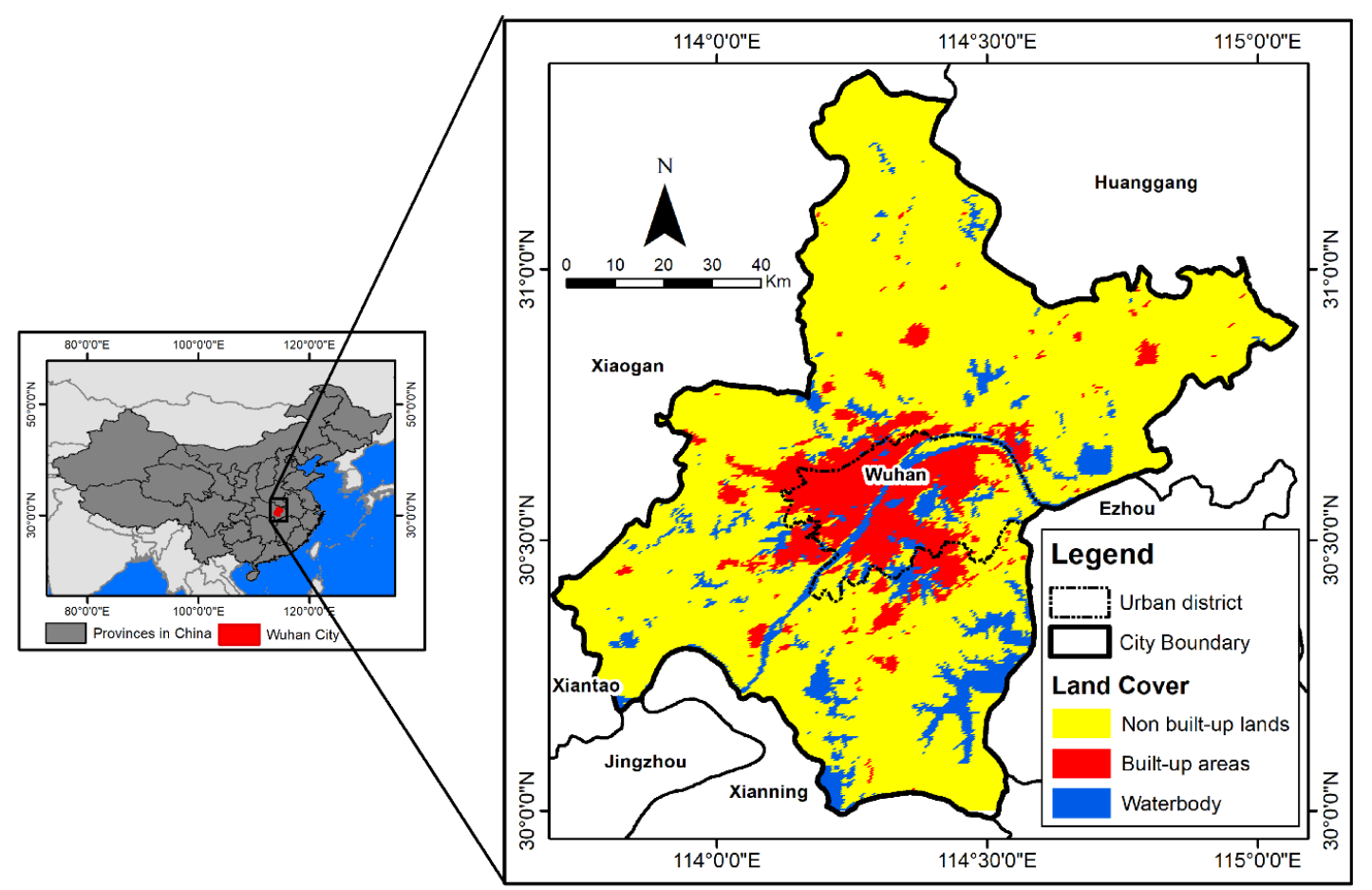

Figure 1. Map of Wuhan City as the study areas represented by generalised MODIS land cover data. 
MODIS imaging data that consisted of MOD11A2 (averaged 8-day LST by Terra satellite at $1 \mathrm{~km}$ spatial resolution), and MCD12Q1 (global land cover dataset at $500 \mathrm{~m}$ spatial resolution) were employed in this study. MOD11A2 LST was generated based on a generalised splitwindow algorithm under cloud-free conditions (Wan, 2013). In terms of LST data, MOD11A2 was chosen instead of MYD11A2 (averaged 8-day LST by Aqua satellite at $1 \mathrm{~km}$ spatial resolution) due to their observation time difference. Terra and Aqua satellite conduct data acquisition around 10.30 AM and 1.30 PM local time, respectively (NASA DAAC, 2020). Some thermal band data with higher spatial resolution such as Landsat 8 and ASTER data observe the earth around 10.30 AM. Consequently, Terra acquisition data was chosen in order to be comparable with further studies using a thermal band with higher spatial resolution in terms of acquisition time.

\subsection{Data processing technique and analysis}

This study compares the LST of two different periods, which are during and before the emergence of COVID-19. The time frame chosen for representing the condition during the emergence of COVID-19 was December 2019, January - February 2020. December 2019, January 2020, and February 2020 represented the time during the beginning phase of the emergence of COVID-19, initiation of lockdown, and few weeks after initiation of lockdown in Wuhan, respectively (Kong et al., 2020; McNeil, 2020). Subsequently, that period would be called as "during COVID-19" period. On the other hand, before the emergence of the COVID-19 period, subsequently called as "before COVID-19" period, referred to the average LST on the same dates with during the COVID-19 period (December to February) for the past three years. For example, the LST of the first week of during COVID-19 period (December 2019) was compared with the average of LST for the past three years (the first week of December 2016, December 2017, and December 2018).

The averaging process of the past three years' data was carried out to minimize LST variation in a particular year before the
COVID-19 period. In addition to minimise the LST variation, averaged 3-year data was employed because there is a possibility of no data value to be compared due to the cloud covers. Besides, to ensure the LST presents the same natural conditions between during and before the emergence of COVID-19, the exact Julian dates were utilised for both periods. Appendix 1 shows the trend of LST data used in this study which matches the 30-year temperature trend in Wuhan. Therefore, even though some weekly data were not generated from the averaged of the previous 3-year data, but the data are still consistent with the temperature trend which already present the seasonal variation in the recorded data. It may affect the LST variation that cannot be erased in this study, yet this is the best available data that can be employed for now. In this study, 8-day data were treated as one week. W1 represented average LST from 3rd to 10th December for the first investigated week, while W12 represented average LST from 26th February to 4th March for the last investigated week during the time frame of this study (Table $1)$.

In general, there were four main processing steps conducted. First, Digital Number (DN) calibration of MOD112 into LST (K) by multiplying DN with 0.02 was done. Then, LST (K) data was converted into Celsius units to ease the interpretation process. Then, the spatial subsetting of LST data became the boundary of Wuhan City. Second, descriptive statistical analysis of during COVID-19 and before COVID-19 periods on a weekly basis throughout the time frame of the study, both in urban and suburbandistricts of Wuhan City, wasconducted. Third, spatio-temporal analysis of LST dynamics throughout the time frame of the research was performed. Fourth, the mean LST differences between during and before COVID-19 periods for each land cover type (Figure 1) with respect to before and during lockdown policy in Wuhan were compared. Land cover was derived from MCD12Q1 in which initially consisted of 13 classes; then, the classes were merged into three mainland cover, i.e., built-up areas, non-built lands, and waterbody. 
Table 1. The date range for each weekly (8-day) LST throughout the study periods.

\begin{tabular}{|c|c|c|c|}
\hline Week (W) & $\begin{array}{l}\text { Beginning Julian Day } \\
\text { (Date range) }\end{array}$ & $\begin{array}{l}\text { Week } \\
\text { (W) }\end{array}$ & $\begin{array}{l}\text { Beginning Julian Day } \\
\text { (Date range) }\end{array}$ \\
\hline W1 & 337 (3rd - 10th Dec) & W7 & 17 (17th - 24th) \\
\hline W2 & 345 (11th - 18th Dec) & W8* & 25 (25th - 1st Feb) \\
\hline W3 & 353 (19th - 26th Dec) & W9 & 33 (2nd - 9th Feb) \\
\hline W4 & 361 (27th - 31st Dec) & W10 & 41 (10th - 17th Feb) \\
\hline W5 & 1 (1st - 8th Jan) & W11 & 49 (18th - 25th Feb) \\
\hline W6 & 9 (9th - 16th Jan) & W12 & 57 (26th Feb - 4th Mar) \\
\hline
\end{tabular}

*Lockdown was started on 23rd January 2020; hence W1 to W7 and W8 to W12 represents before and during lockdown conditions, respectively

Table 2. Processed MODIS 8-day LST data.

\begin{tabular}{|c|c|c|c|c|c|c|c|c|c|c|c|c|}
\hline \multirow[b]{2}{*}{ Period } & \multicolumn{4}{|c|}{ December } & \multicolumn{4}{|c|}{ January } & \multicolumn{4}{|c|}{ February } \\
\hline & W1 & W2 & W3 & W4 & W5 & W6 & W7 & W8 & W9 & W10 & W11 & W12 \\
\hline \multicolumn{13}{|l|}{$\begin{array}{l}\text { During } \\
\text { COVID-19 }\end{array}$} \\
\hline$(2019 / 20)$ & $\checkmark$ & $\checkmark$ & I & $\checkmark$ & I & $\checkmark$ & $\checkmark$ & $\checkmark$ & I & $\checkmark$ & $\checkmark$ & I \\
\hline \multicolumn{13}{|l|}{$\begin{array}{l}\text { Before } \\
\text { COVID-19 }\end{array}$} \\
\hline 2018/19 & $x$ & $\checkmark$ & $x$ & $x$ & $x$ & $x$ & $\checkmark$ & $x$ & $x$ & $x$ & $x$ & $x$ \\
\hline $2017 / 18$ & $\checkmark$ & $\checkmark$ & $\checkmark$ & $x$ & $x$ & $\checkmark$ & $x$ & $x$ & $x$ & $\checkmark$ & $\checkmark$ & $x$ \\
\hline 2016/17 & $\checkmark$ & $\checkmark$ & $X$ & $\checkmark$ & I & $\checkmark$ & $\checkmark$ & $\checkmark$ & I & $\checkmark$ & $\checkmark$ & $\checkmark$ \\
\hline \multicolumn{13}{|l|}{ Notes: } \\
\hline \multicolumn{13}{|c|}{$\checkmark=$ data has insignificant cloud cover } \\
\hline \multicolumn{13}{|c|}{$X=$ data is unable to process due to vast cloud covers } \\
\hline I = data $\mathrm{wa}$ & terpc & $\mathrm{ed} b$ & ed or & he pr & lous & d ne & 8-da & ata & to & ud co & & \\
\hline
\end{tabular}

There were two limitations in this study, including (1) cloud-free data availability and (2) differences in cloud-free areas for some scenes. Some scenes only contained a small portion of cloud-free areas, e.g., W1 of 2018/19 and W4 of 2017/18 (Table 2). In order to overcome this issue, some data were interpolated by averaging the data based on the previous and next 8-day data, e.g., W3 in during the Covid-19 period was filled by averaging LST of W2 and W3 of during COVID-19 period. Based on the average of 30-year data, temperature trends in Wuhan is regular from month to month (China Meterological Administration, n.d.). For example, temperature tends to experience a decline from December to January and an increase from January to February and so on. Hence, the interpolation conducted based on the previous and the next 8-day for filling a particular week due to vast cloud cover is likely to give representative results and still follows the temperature trends from time to time (Appendix 1).

In cases of before COVID-19 period where one or two out of three datasets were unavailable for a particular week, then only the available data were employed. For example, W4 of before COVID-19 period did not have data for W4 of 2017/18 and 2018/19 periods, then W4 of 2016/17 was employed to represent W4 of before COVID-19 LST, instead of averaging LST of W4 for the past threeyear data. The second issue, which was the differences in cloud-free areas for some scenes, was overcome by considering the intersection areas of all scenes. Hence, the coverage areas among the scenes were consistent. 


\section{Results and Discussion}

3.1. The mean LST differences between during and before the emergence of COVID-19

Table 3 shows the results of descriptive statistics of LST for during and before Covid-19 conditions over the time frame of the study. In general, minimum LST tended to be lower during COVID-19 periods than before COVID-19 periods for both before and during lockdown policy were applied, except for W2, W3, and W11 in which the minimum LST of the during COVID-19 periods witnessed relatively higher value. In terms of maximum LST, before COVID-19 periods, it tended to exhibit relatively lower maximum LST in comparison to during COVID-19 periods, except for weeks 6-8, and 11-12. To sum up, there was no distinct pattern of minimum and maximum LST for during and before COVID-19 periods with respect to before and during the implementation of lockdown policy in Wuhan City.

With regards to the mean LST for during and before COVID-19 periods, it can be observed that before lockdown policy was applied, mean LST during COVID-19 periods tended to experience higher value than before COVID-19 periods. In contrast, relatively lower mean LST values during COVID-19 than before COVID-19 periods were observed during lockdown policy was applied, except for W11, in which the mean LST during the COVID-19 period showed higher value than before COVID-19 period. In other words, before the lockdown policy was applied, the mean LST during COVID-19 conditions tended to exhibit relatively higher value than before COVID-19. However, during lockdown policy was applied, mean LST values of before COVID-19 conditions were higher than during COVID-19 conditions. Those results were supported by the differences of mean LST during COVID-19 conditions minus mean LST of before COVID-19 conditions. In general, before lockdown conditions were likely to show positive values representing higher values during COVID-19 conditions, while during lockdown conditions were likely to show negative values representing lower values before COVID-19 conditions.

Table 3. Descriptive statistic LST of before and during COVID-19 conditions over the study periods.

\begin{tabular}{|c|c|c|c|c|c|c|c|}
\hline \multirow[b]{2}{*}{ Week } & \multicolumn{2}{|c|}{ Min LST $\left({ }^{\circ} \mathrm{C}\right)$} & \multicolumn{2}{|c|}{$\operatorname{Max} \operatorname{LST}\left({ }^{\circ} \mathrm{C}\right)$} & \multicolumn{2}{|c|}{ Mean LST $\left({ }^{\circ} \mathrm{C}\right)$} & \multirow{2}{*}{$\begin{array}{c}\text { Mean Difference }\left({ }^{\circ} \mathrm{C}\right) \\
\text { (during COVID minus } \\
\text { before COVID) }\end{array}$} \\
\hline & $\begin{array}{c}\text { before } \\
\text { COVID }\end{array}$ & $\begin{array}{l}\text { during } \\
\text { COVID }\end{array}$ & $\begin{array}{l}\text { before } \\
\text { COVID }\end{array}$ & $\begin{array}{l}\text { during } \\
\text { COVID }\end{array}$ & $\begin{array}{l}\text { before } \\
\text { COVID }\end{array}$ & $\begin{array}{l}\text { during } \\
\text { COVID }\end{array}$ & \\
\hline $\mathrm{W} 1$ & 9.15 & 8.85 & 18.44 & 18.71 & 13.42 & 13.55 & 0.14 \\
\hline W2 & 6.96 & 10.43 & 16.42 & 21.05 & 10.71 & 15.98 & 5.27 \\
\hline W3 & 7.23 & 9.11 & 16.67 & 18.00 & 12.16 & 13.29 & 1.14 \\
\hline W4 & 6.01 & 4.45 & 14.59 & 15.05 & 9.47 & 10.60 & 1.14 \\
\hline W5 & 5.87 & 3.89 & 14.12 & 14.33 & 9.23 & 9.87 & 0.64 \\
\hline W6 & 5.46 & -2.53 & 14.43 & 13.79 & 9.00 & 9.14 & 0.14 \\
\hline W7 & 5.45 & 5.13 & 14.70 & 13.77 & 9.62 & 9.42 & -0.20 \\
\hline$W 8^{*}$ & 7.45 & 6.37 & 18.37 & 17.07 & 13.50 & 11.47 & -2.04 \\
\hline W9 & 7.36 & 6.64 & 17.29 & 18.33 & 12.95 & 11.45 & -1.51 \\
\hline W10 & 5.20 & 4.63 & 17.74 & 20.17 & 12.41 & 11.43 & -0.97 \\
\hline W11 & 6.61 & 8.89 & 20.47 & 19.37 & 14.42 & 14.86 & 0.44 \\
\hline W12 & 10.53 & 9.69 & 23.27 & 20.75 & 16.24 & 15.85 & -0.39 \\
\hline
\end{tabular}




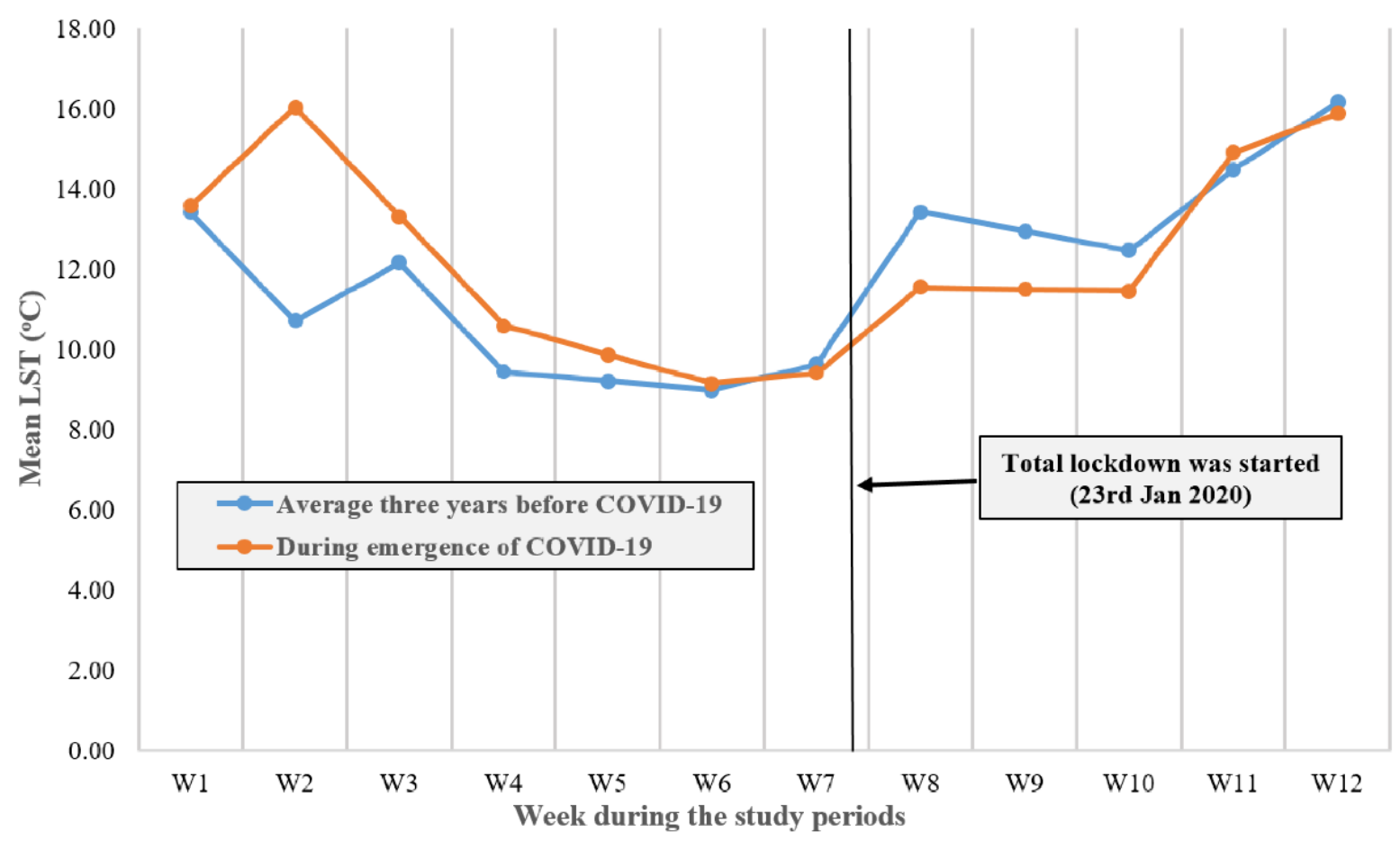

Figure 2. Mean LST comparison between during and before the emergence of COVID-19 in suburban districts.

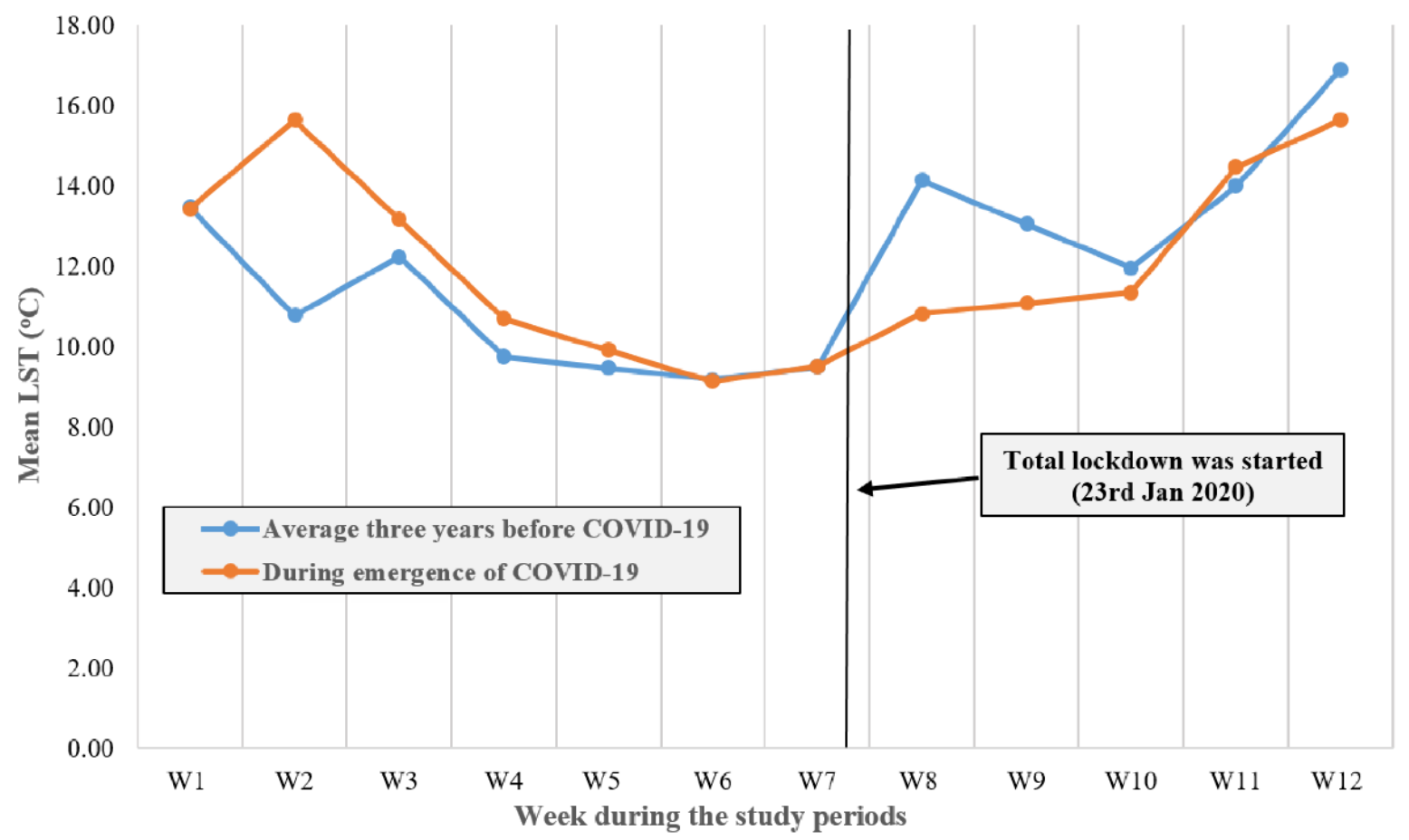

Figure 3. Mean LST comparison between during and before the emergence of COVID-19 in urban districts.

Trend comparison of mean LST values throughout the study period for suburban and urban districts of Wuhan City is presented in Figure 2 and Figure 3, respectively. In general, both locations showed similar mean LST trends over the time frame of this study. Overall, before the lockdown policy was applied, the mean LST during COVID-19 conditions tended to experience relatively higher LST than before COVID-19 conditions, except for W7. 
Then, during lockdown policy was applied, in contrast, mean LST during COVID-19 conditions tended to experience relatively lower LST than before COVID-19 conditions, except for W11. In addition, both locations exhibited the lowest value in December then experienced a rebound until the end of the time frame of the study. However, the gap of mean LST values between during and before COVID-19 periods tended to be wider in suburban than in urban districts of Wuhan City, both in before and during lockdown policy were applied.

\subsection{Spatio-temporal analysis of the} average LST between during and before the emergence of COVID-19

Aggregation of mean LST in terms of prior to the implementation of lockdown policy during the COVID-19 period as well as the average of the past three years before the emergence of COVID-19 on the same dates is illustrated by Figure $4 \mathrm{a}$ and Figure $4 \mathrm{~b}$, respectively. In addition, aggregation of mean
LST in terms of during implementation of lockdown policy during the COVID-19 period and the average of the past three years before the emergence of COVID-19 on the same dates are illustrated by Figure $5 a$ and Figure $5 b$, respectively. The interval classes of mean LST were set to be consistent for all compared maps so that spatio-temporal comparisons could be investigated. Basically, the mean LST in all conditions showed a relatively similar pattern throughout the whole study area. In suburban districts, the north-western sectors tended to exhibit relatively lower temperatures than the rest of the suburban district areas, except for some places in which water bodies were spread, for example, in the south-eastern parts of Wuhan City. Furthermore, in urban districts, mean LST values tended to be irregularly distributed. However, a heat island patch was observed in the north-western part of the urban district. Besides, in the south of the heat island patch of the urban district, there were small portions of low LST areas which corresponded to water bodies.
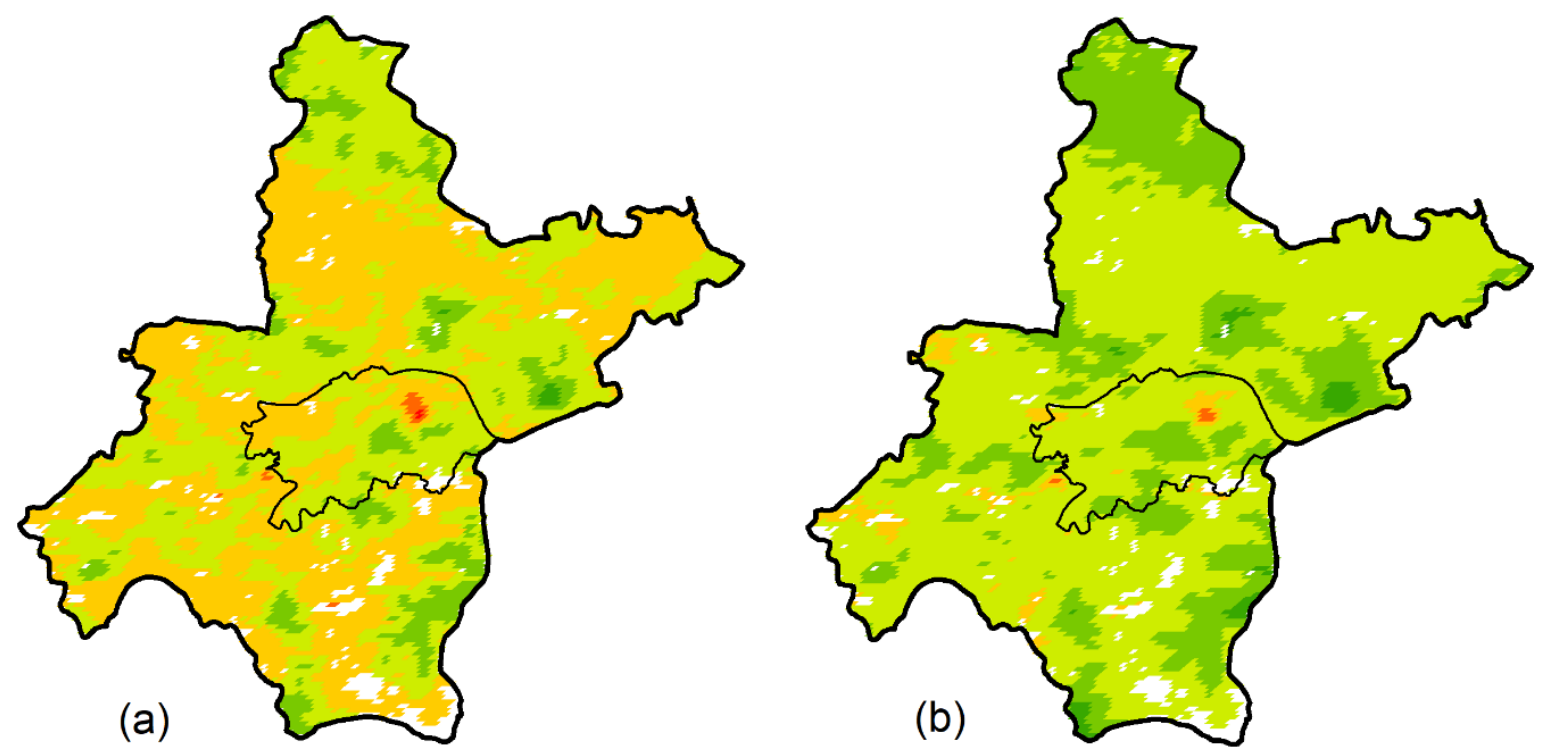

Mean LST $\left({ }^{\circ} \mathrm{C}\right)$

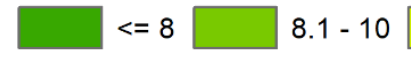

$10.1-12$

$12.1-14$

$14.1-16$ $>16$

Figure 4. Mean LST comparison during the period of 3rd December to 24th January between (a) during the COVID-19 period prior to the implementation of lockdown policy, (b) average of the past three years before the emergence of COVID-19 on the same dates with during COVID-19 period. White pixels inside the administrative boundary represents NoData value. 


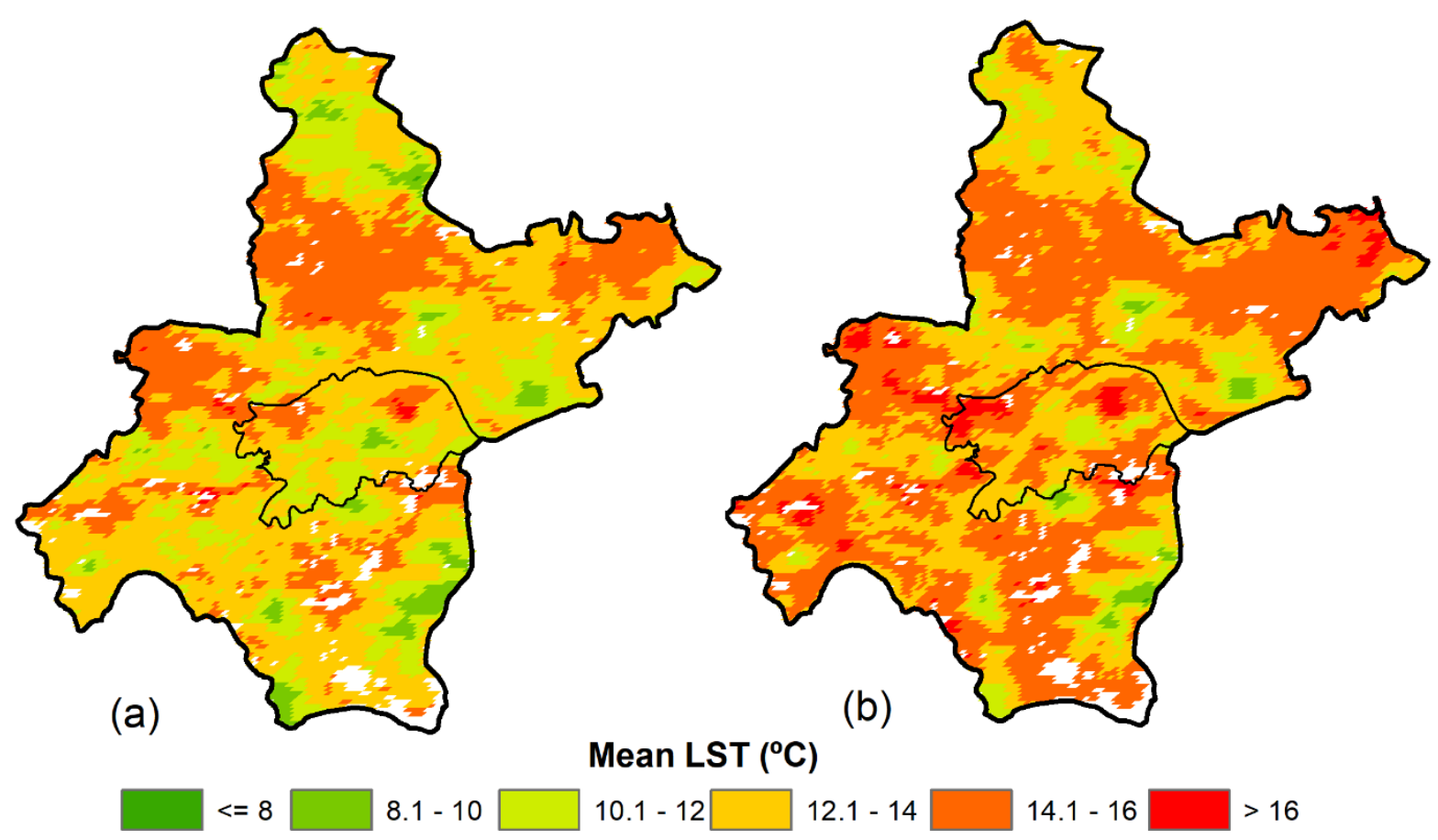

Figure 5. Mean LST comparison during the period of 25th January to 4th March between (a) during the COVID-19 period during the implementation of lockdown policy, (b) average of the past three years before the emergence of COVID-19 on the same dates with during COVID-19 period. White pixels inside the administrative boundary represents NoData value.

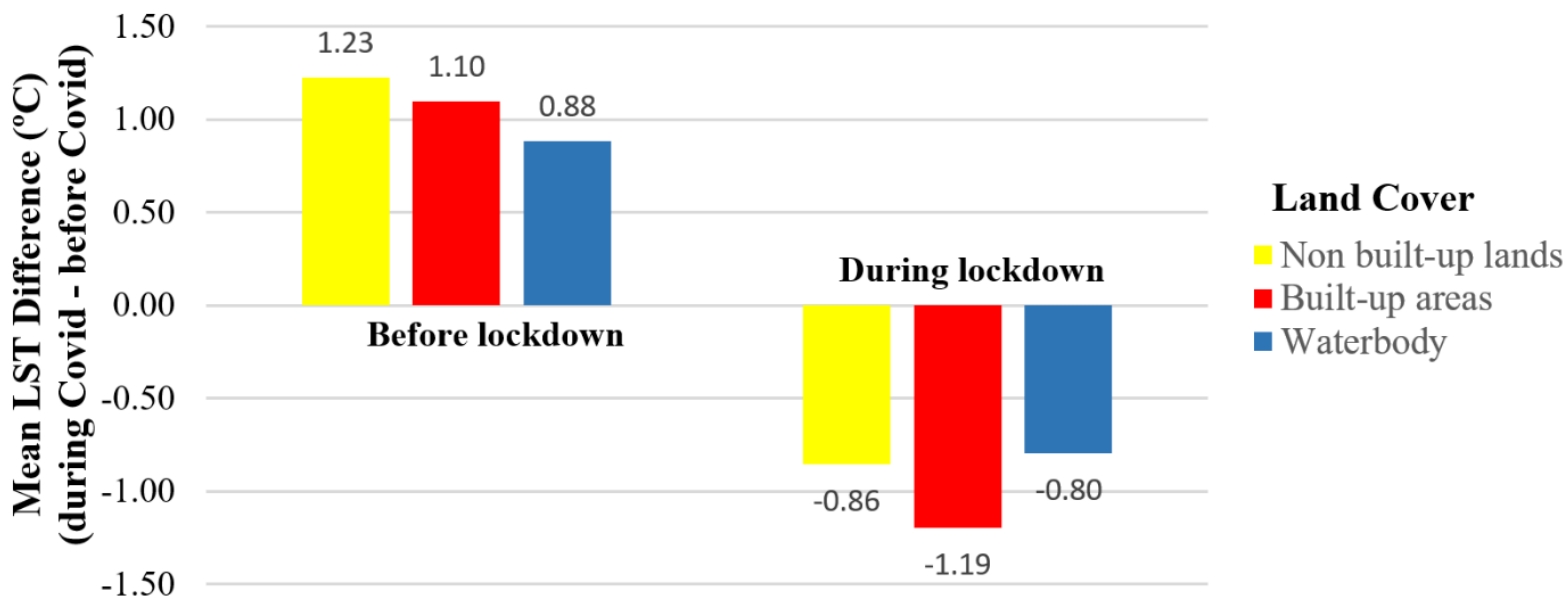

\section{Period of mean LST comparison}

Figure 6. Mean LST differences between during COVID-19 period minus before the emergence of COVID-19 period concerning the implementation of lockdown policy for each land cover.

In terms of temporal aspects, in this case, before lockdown policy was applied, mean LST aggregation during the COVID-19 period exhibited higher value than the average of the past three years before the emergence of COVID-19 on the same dates. It is presented by the more areas with orange colour rather than green colour in the map during COVID-19 before the lockdown was applied. On the contrary, during lockdown policy was implemented, mean LST aggregation during COVID-19 period witnessed lower value than the average of the previous three years before the emergence of COVID-19 on the same dates, 
as presented by a smaller portion of orange and red colours in the map of during COVID-19 in comparison to the map of before the emergence of COVID-19.

\subsection{Mean LST differences for each land cover type between during and before the emergence of COVID-19 concerning the implementation of lockdown policy}

Figure 6 illustrates mean LST differences as the results of mean LST during the COVID-19 period subtracted by mean LST before the emergence of the COVID-19 period for each land cover type, as without and with the implementation of lockdown policy. Overall, the waterbody exhibited the smallest mean LST differences for both before and during the implementation of lockdown policy by $0.88^{\circ} \mathrm{C}$ and $-0.80^{\circ} \mathrm{C}$, respectively. To be more specific, before lockdown policy was applied, non-builtup lands exhibited the most significant mean LST difference between during COVID-19 and the average of the past three years before the emergence of COVID-19 period, which means that the average LST for non-built-up lands during the emergence of COVID-19 was higher than the average of the past three years before the emergence of COVID-19 period by 1.23 ${ }^{\circ} \mathrm{C}$, then followed by built-up areas by $1.10^{\circ} \mathrm{C}$. Furthermore, during lockdown policy applied, the most significant mean LST difference between during COVID-19 and the average of the past three years before the emergence of the COVID-19 period was observed in built-up areas by $-1.19{ }^{\circ} \mathrm{C}$ and followed by non-builtup lands by $-0.86{ }^{\circ} \mathrm{C}$. In other words, during lockdown condition, mean LST during the COVID-19 period was below the average of the past three years on the same dates by 1.19 ${ }^{\circ} \mathrm{C}$ and $0.86{ }^{\circ} \mathrm{C}$ for built-up and non-built-up lands, respectively.

\subsection{Discussion}

Previous studies show that, in general, LST tends to increase from time to time due to land use land cover (LULC) changes, urban growth, and/or the increase of human population (Singh, Kikon, \& Verma, 2017;
Walawender, Szymanowski, Hajto, \& Bokwa, 2014; Zhan, Meng, \& Xiao, 2015). However, this research pointed to significant results in which average LST is decreasing during the selected period of time, which might be due to the diminishing of anthropogenic activities. This study showed that the mean LST during the emergence of COVID-19 without lockdown policy applied, i.e., early December 2019 to late January 2020 (Figure 4a), was relatively higher than the mean LST of the previous three years before the emergence of COVID-19 on the same dates (Figure $4 b$ ), for both urban and suburban districts of Wuhan. Whereas, the mean LST during the emergence of COVID-19 with lockdown policy applied, i.e., late January to early March 2020 (Figure 5a), was relatively lower than the mean LST of the previous three years on the same dates (Figure 5b), for both urban and suburban districts of Wuhan. This study, therefore, indicates that LST is not always increasing from time to time as the expansion of built-up areas and the increase of the human population. It may decrease with a particular approach to suppress anthropogenic heat discharge, such as a lockdown policy. This study also confirms a study conducted by L. Li et al. (2014) that anthropogenic activities had an important effect on controlling LST and added another point of the positive impact of lockdown to the environment of the city, such as Wuhan (Lau et al., 2020).

Based on MODIS land cover data at $500 \mathrm{~m}$ resolution (Figure 1), generally, Wuhan's urban district accounts for a higher proportion of built-up areas in comparison with the Wuhan's suburban districts. However, it should be noted that the land cover data resolution used in this study was coarse so that it tended to reduce the accuracy of the land cover type proportion, especially the built-up areas and waterbody. In the land cover dataset used in this study, a pixel of $500 \mathrm{~m}$ resolution would be assigned to built-up areas and waterbody if at least 30\% and $60 \%$ of the $500 \mathrm{~m}^{2}$ consisted of impervious areas and permanent waterbody, respectively (Sulla-Menashe \& Friedl, 2018). As a result, in suburban districts, there was a likelihood of 
eliminating pixels of low-density built-up areas and waterbody due to these caveats, whereas these two land cover types gave contradictory influences in LST distribution (Gartland, 2011).

In general, LST value distribution across Wuhan City tended to be irregularly distributed. In terms of the spatial distribution of LST, a patch of relatively higher temperature areas in the urban district throughout the study time frame was observed. It turned out that there was an iron and steel company based on observation by Google Maps. In contrast, some consistent areas with relatively low LST areas were observed. First, some parts in the northwestern and north-eastern parts of Wuhan City land covers are forest. Second, water bodies are distributed across the Wuhan. These details can be observed in the study conducted by Ke, Zheng, Zhou, and Liu (2017), which utilised higher spatial resolution data.

Forest and waterbody cover tend to witness relatively lower LST than built-up areas due to the capability of retaining water for conducting evaporative cooling. Land covers with moisture such as forest and waterbody increase latent heat flux and inhibit the transfer of sensible heat; in contrast, dry urbanised areas magnify the transfer of sensible heat and inhibit latent heat flux (Shahmohamadi, Che-Ani, Maulud, Tawil, \& Abdullah, 2011). Besides, the waterbody tends to have stable temperatures from time to time due to its capability to regulate heat, employing the convection process throughout all parts of the waterbody (Jensen, 2014). Accordingly, the aforementioned conditions might be the reason behind the lowest mean LST differences between during and before the emergence of COVID-19 in a water body, as shown in Figure 6 , regardless of the intensity of human activities due to lockdown.

Basically, built-up areas tend to exhibit relatively higher temperature than the surrounding of non-built areas for several reasons, such as the land surface characteristics itself and anthropogenic activities conducted on built-up areas (Shahmohamadi et al., 2011). According to Gartland (2011), in terms of surface characteristics, built-up areas that consist of impervious surfaces and buildings can enhance LST due to less available moisture to evaporate. In addition, dark-coloured materials with canyon-like shapes of pavements and buildings confine incoming shortwave radiation from the sun. Furthermore, canyon-like configurations of the building also minimise wind speed in the urbanised areas. As a result, low wind speed tends to reduce evaporative cooling (Lee, 1984).

Before lockdown, the mean LST difference between during the emergence of COVID-19 emergence and the past 3 years (2016-2018) is presented as positive difference which means that the mean LST during the emergence of COVID-19 (2019/2020) is higher than the past 3 years. Land cover classification used to compare both periods was generated using MCD12Q1 product (global land cover dataset at $500 \mathrm{~m}$ spatial resolution). The classification is categorised based on the percentage of land cover within a pixel $(500 \mathrm{~m})$, a pixel is classified as built up area if at least $30 \%$ impervious surface area including building materials, asphalt, and vehicles (Sulla-Menashe \& Friedl, 2018). If the percentage of impervious area is less than $30 \%$, then it is classified as non-built up lands. This classification technique implies that non-built up lands might consist of some built-up areas up to $29 \%$ in a pixel of $500 \mathrm{~m}^{2}$. In addition, non-built-up lands are dominant in suburban districts. The cumulative effect of non-built-up lands that might consist of builtup areas below $30 \%$ could be the underlying reason behind the higher LST difference for non-built up lands in comparison to built-up areas before lockdown.

Regarding anthropogenic activities, urban areas are the main sources of anthropogenic heat discharge from manufacturing, transportation, lighting, cooling, and heating buildings (Gartland, 2011). Moreover, the role of anthropogenic activities in terms of releasing heat is significant during winter (Offerle, Grimmond, Fortuniak, Kłysik, \& Oke, 2006). As a result, relatively higher temperatures in urbanised areas are not only influenced by the land cover, but also the 
human activities (anthropogenic heating) in particular areas. Therefore, when human activities are decreasing during the lockdown period, then there is a likelihood of a decrease in LST in Wuhan City. In addition, previously mentioned ideas could be the explanation of the most significant differences in mean LST of built-up areas, where mean LST of built-up areas during the emergence of COVID-19 with lockdown policy applied in Wuhan was lower than the mean LST of the previous three years on the same dates by $1.19^{\circ} \mathrm{C}$. Meanwhile, nonbuilt-up lands and waterbody were just 0.86 ${ }^{\circ} \mathrm{C}$ and $0.80{ }^{\circ} \mathrm{C}$, respectively, as presented in Figure 6.

\section{Conclusions}

This study has compared mean LST differences between during the emergence of COVID-19 and the average of the past three years for the same dates representing before the emergence of COVID-19 in Wuhan City. Results showed that during the emergence of COVID-19 with lockdown policy applied, i.e. late January 2020 to early March 2020, the mean LST was lower than the mean LST of the past three years on the same dates. Whereas, during the emergence of COVID-19 without lockdown policy applied, i.e. early December 2019 to late January 2020, the mean LST was relatively higher than the mean LST of the past three years.

In terms of spatial distribution, LST value distribution across Wuhan City tended to be irregularly distributed. However, some parts of Wuhan city witnessed consistent low temperatures throughout the time frame of the study, i.e., waterbody and forest cover. That land covers shape low temperatures across the study areas due to the capability of retaining water for conducting evaporative cooling. In addition, this study showed that among three land covers, i.e., non-built-up areas, builtup areas, and waterbody, mean LST of builtup areas experienced the most significant differences between during emergence of COVID-19 with lockdown policy applied in comparison to the average of the past three years on the same dates. In this case, the mean LST of built-up areas during the emergence of COVID-19 with lockdown policy applied was lower than the mean LST of the previous three years on the same dates by $1.19^{\circ} \mathrm{C}$, whereas non-built-up lands and waterbody were just $0.86^{\circ} \mathrm{C}$ and $0.80{ }^{\circ} \mathrm{C}$, respectively.

This study concludes that LST is not always increasing from time to time as the expansion of built-up areas and the increase of the human population. However, a decrease in anthropogenic activities might also contribute to suppressing anthropogenic heat discharge, which leads to lowering LST, especially in built-up areas. Last, the conclusions of this study should be taken cautiously. It is due to some data interpolation, which was conducted to compensate for the unavailable dataset due to significant cloud covers. Also, some possible confounding factors contribute to the LST dynamics which have not been investigated in this study. In addition, further studies should focus on evaluating LST over quarantined cities using higher spatial resolution data. Besides, incorporation of weather data from field observations to the experiment is likely to present a thorough explanation of the phenomena under investigation.

\section{Acknowledgements}

The authors would like to express the gratitude to NASA for providing MODIS data. Also, the authors would like to extend our gratitude to the publisher for giving us a chance to disseminate our research in such a reputable journal.

\section{References}

Avdan, U., \& Jovanovska, G. (2016). Algorithm for automated mapping of land surface temperature using LANDSAT 8 satellite data. Journal of Sensors, 2016, 1-8. doi:10.1155/2016/1480307

Buyantuyev, A., \& Wu, J. (2010). Urban heat islands and landscape heterogeneity: linking 
spatiotemporal variations in surface temperatures to land-cover and socioeconomic patterns. Landscape Ecology, 25(1), 17-33. doi:10.1007/s10980-009-9402-4

China Meteorological Administration (n.d.). Climate in China. Retrieved from http://data.cma. cn/data/weatherBk.html [26th April 2020]

Eleftheriou, D., Kiachidis, K., Kalmintzis, G., Kalea, A., Bantasis, C., Koumadoraki, P., ... Gemitzi, A. (2018). Determination of annual and seasonal daytime and nighttime trends of MODIS LST over Greece - climate change implications. Science of The Total Environment, 616-617, 937-947. doi: 10.1016/j.scitotenv.2017.10.226

Esfandiari, S. (2020). These are all the companies who have shut down operations in China over the deadly Wuhan coronavirus outbreak. Retrieved from https://www.businessinsider. sg/wuhan-coronavirus-which-companies-shut-down-operations-move-employees-2020$1 ? \mathrm{r}=\mathrm{US} \& \mathrm{IR}=\mathrm{T}[26 \mathrm{th}$ April 2020]

Gartland, L. (2011). Heat islands: understanding and mitigating heat in urban areas. London: Earthscan.

Hulley, G. C., Hughes, C. G., \& Hook, S. J. (2012). Quantifying uncertainties in land surface temperature and emissivity retrievals from ASTER and MODIS thermal infrared data. Journal of Geophysical Research: Atmospheres, 117(D23). doi:10.1029/2012JD018506

Jensen, J. R. (2014). Remote sensing of the environment: an earth resource perspective. Essex: Pearson.

Jensen, J. R. (2015). Introductory Digital Image Processing: A Remote Sensing Perspective. One Lake Street Upper Saddle River, NJ: Prentice Hall.

Ke, X., Zheng, W., Zhou, T., \& Liu, X. (2017). A CA-based land system change model: LANDSCAPE. International Journal of Geographical Information Science, 31(9), 1798-1817. doi:10.1080/13658 816.2017.1315536

Kong, W.-H., Li, Y., Peng, M.-W., Kong, D.-G., Yang, X.-B., Wang, L., \& Liu, M.-Q. (2020). SARSCoV-2 detection in patients with influenza-like illness. Nature Microbiology, 5(5), 675-678. doi:10.1038/s41564-020-0713-1

Kuo, L. (2020). Coronavirus: China bars $11 \mathrm{~m}$ residents from leaving city at centre of outbreak. Retrieved from https://www.theguardian.com/world/2020/jan/22/coronavirus-chinameasures-rein-spread-mutate-disease-death-toll [28th April 2020]

Lau, H., Khosrawipour, V., Kocbach, P., Mikolajczyk, A., Schubert, J., Bania, J., \& Khosrawipour, T. (2020). The positive impact of lockdown in Wuhan on containing the COVID-19 outbreak in China. Journal of Travel Medicine. doi:10.1093/jtm/taaa037

Lee, D. O. (1984). Urban climates. Progress in Physical Geography: Earth and Environment, 8(1), 1-31. doi:10.1177/030913338400800101

Li, L., Tan, Y., Ying, S., Yu, Z., Li, Z., \& Lan, H. (2014). Impact of land cover and population density on land surface temperature: case study in Wuhan, China. Journal of applied remote sensing, 8(1), 084993. doi: 10.1117/1.JRS.8.084993

Li, X., Li, W., Middel, A., Harlan, S. L., Brazel, A. J., \& Turner, B. L. (2016). Remote sensing of the surface urban heat island and land architecture in Phoenix, Arizona: Combined effects of land composition and configuration and cadastral-demographic-economic factors. Remote Sensing of Environment, 174, 233-243. doi: 10.1016/j.rse.2015.12.022

Liu, J., Zhou, J., Yao, J., Zhang, X., Li, L., Xu, X., . . Zhang, K. (2020). Impact of meteorological factors on the COVID-19 transmission: A multi-city study in China. Science of The Total Environment, 726, 138513. doi: 10.1016/j.scitotenv.2020.138513 
McNeil, S. (2020). Wuhan Celebrates the End of Its 76-Day Coronavirus Lockdown Retrieved from https:/ / time.com/5816938/wuhan-coronavirus-lockdown-ends/ [27th April 2020]

Meng, C., \& Dou, Y. (2016). Quantifying the anthropogenic footprint in eastern china. Scientific Reports, 6, 24337. doi:10.1038/srep24337

NASA DAAC. (2020). Terra vs. Aqua Retrieved from https://nsidc.org/data/modis/terra_ aqua_differences [28th April 2020]

Ndossi, M. I., \& Avdan, U. (2016). Application of Open Source Coding Technologies in the Production of Land Surface Temperature (LST) Maps from Landsat: A PyQGIS Plugin. Remote Sensing, 8(5). doi:10.3390/rs8050413

Offerle, B., Grimmond, C. S. B., Fortuniak, K., Kłysik, K., \& Oke, T. R. (2006). Temporal variations in heat fluxes over a central European city centre. Theoretical and Applied Climatology, 84(1), 103-115. doi:10.1007/s00704-005-0148-x

Qin, A., \& Hernández, J. C. (2020). China Reports First Death from New Virus - The New York Times. Retrieved from https://www.nytimes.com/2020/01/10/world/asia/china-viruswuhan-death.html [25th April 2020]

Shahmohamadi, P., Che-Ani, A. I., Maulud, K. N. A., Tawil, N. M., \& Abdullah, N. A. G. (2011). The impact of anthropogenic heat on formation of urban heat island and energy consumption balance. Urban Studies Research, 2011, 1-9. doi:10.1155/2011/497524

Singh, P., Kikon, N., \& Verma, P. (2017). Impact of land use change and urbanization on urban heat island in Lucknow city, Central India. A remote sensing based estimate. Sustainable Cities and Society, 32, 100-114. doi: 10.1016/j.scs.2017.02.018

Sulla-Menashe, D., \& Friedl, M. A. (2018). User Guide to Collection 6 MODIS Land Cover (MCD12Q1 and MCD12C1) Product [Product Specification Guide]. Retrieved from https://lpdaac.usgs. gov/documents/101/MCD12_User_Guide_V6.pdf

Tobías, A., Carnerero, C., Reche, C., Massagué, J., Via, M., Minguillón, M. C., . . Querol, X. (2020). Changes in air quality during the lockdown in Barcelona (Spain) one month into the SARS-CoV-2 epidemic. Science of the Total Environment, 726, 138540. doi: 10.1016/j. scitotenv.2020.138540

Walawender, J. P., Szymanowski, M., Hajto, M. J., \& Bokwa, A. (2014). Land Surface Temperature Patterns in the Urban Agglomeration of Krakow (Poland) Derived from Landsat-7/ETM+ Data. Pure and Applied Geophysics, 171(6), 913-940. doi:10.1007/s00024-013-0685-7

Wan, Z. (2013). Collection-6 MODIS Land Surface Temperature Products Users' Guide [Product Specification Guide]. Retrieved from https://lpdaac.usgs.gov/documents/118/MOD11_ User_Guide_V6.pdf [28th April 2020]

Wang, Y., Zhan, Q., \& Ouyang, W. (2017). Impact of urban climate landscape patterns on land surface temperature in wuhan, china. Sustainability, 9(10), 1700. doi:10.3390/su9101700

World Health Organisation. (2020a). Coronavirus disease (COVID-19) outbreak. Retrieved from https://www.who.int/westernpacific/emergencies/covid-19 [28th April 2020]

World Health Organisation. (2020b). Novel Coronavirus (2019-nCoV) Situation Report 1 - 21 January 2020 [Report]. Retrieved from https://www.who.int/docs/default-source/ coronaviruse/situation-reports/20200121-sitrep-1-2019-ncov.pdf?sfvrsn=20a99c10_4 [26th April 2020]

Yoo, C., Im, J., Park, S., \& Cho, D. (2017). Thermal Characteristics of Daegu using Land Cover 
Data and Satellite-derived Surface Temperature Downscaled Based on Machine Learning. Korean Journal of Remote Sensing, 33(6_2), 1101-1118. doi:10.7780/KJRS.2017.33.6.2.6

Zhan, Q., Meng, F., \& Xiao, Y. (2015). Exploring the relationships of between land surface temperature, ground coverage ratio and building volume density in an urbanized environment. ISPRS - International Archives of the Photogrammetry, Remote Sensing and Spatial Information Sciences, XL-7/W3, 255-260. doi:10.5194/isprsarchives-XL-7-W3-255-2015

\section{Appendix}

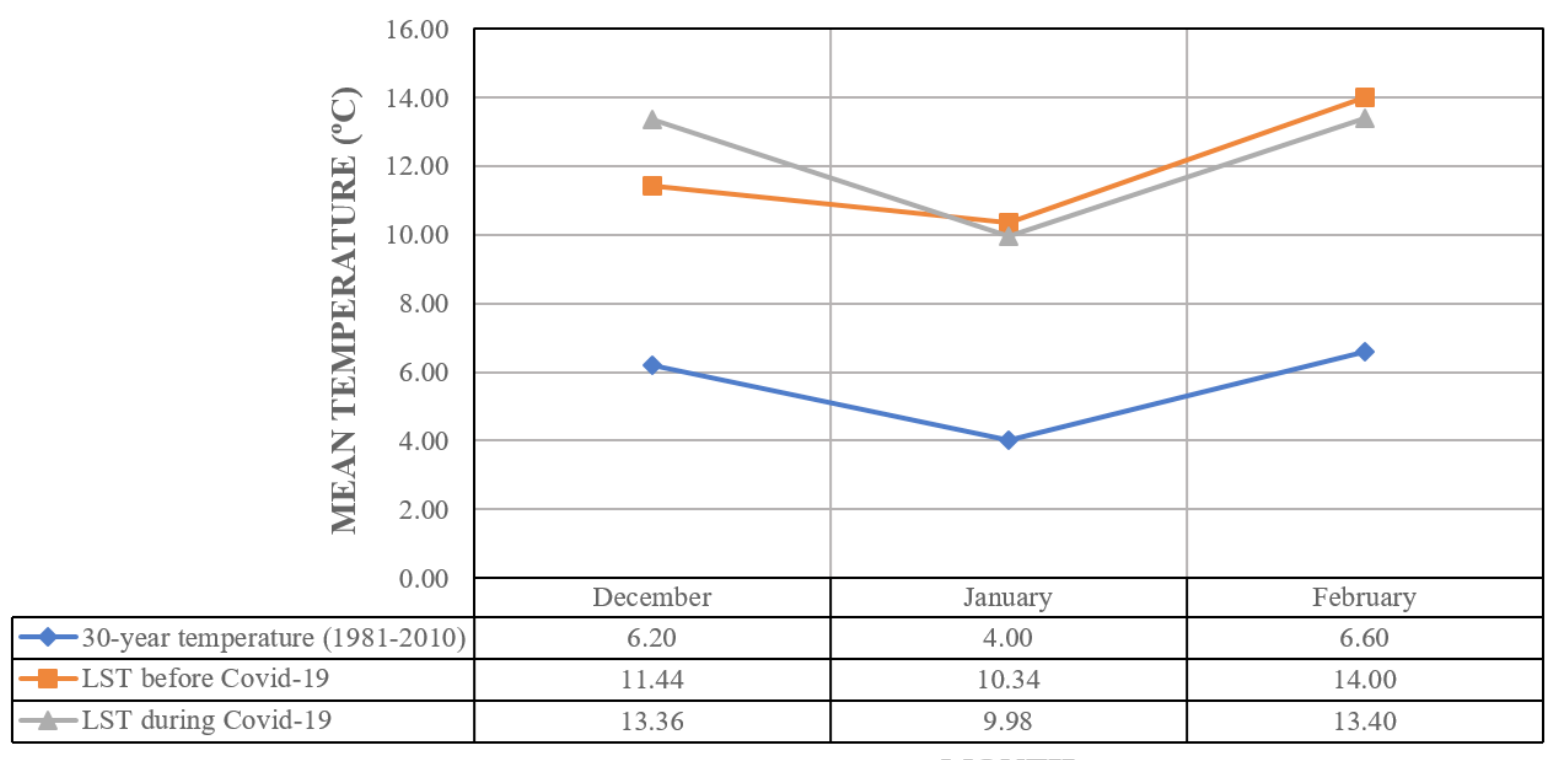

MONTH

Appendix 1. Trend comparison of average 30-year (1981-2010) temperature, LST before and during COVID-19 in Wuhan City 